einer Minute 100 Sternschnuppen sichtbar wurden. Gegen 9 Uhr wurde die Beobachtung ein wenig durch Wolken unterbrochen, und dabei lenkte ich meine Aufmerksamkeit darauf, ob etwa eine der Sternschnuppen nicht unterhalb der Wolken aufblitzt; davon aber habe ich garnichts bemerkt. Die Wolken, welche nur eine Fortsetzung eines uber dem Nordhorizonte von der Stadt rorbeiziehenden Gewitters zu sein schienen, hatten eine unbedentende Höhe. Um $9 \frac{1}{4}$ Uhr war wieder der Himmel ganz klar, die Erscheinung wieder in ihrem fruheren Glanze, ja sogar manchmal noch prachtvoller, als früher, denn um $9 \frac{1}{2}$ Uhr zähite ich blos in der Verticalzone zwischen dem Pegasus und der Milchstrasse 47 Sternschnuppen in der Zeit ron $1 \frac{1}{2}$ Minuten. Nach 10 Uhr schien die Anzahl der Sternschnuppen unbedeutend sich zu vermindern, wach 11 Uhr kamen wieder Wolken heran und die weitere Beobachtung musste aufgegehen werden.

- Während des ganzen Phänomens liessen sich längere Unterbrechungen im Sternschnuppenfall nicht wathrnehmen, wiewohl anderseits von Zeit zu Zeit einige Oscillationen darin stattzufinden schienen.

In Bezug auf die Richtung des Laufes der Sternschnuppen, kann ich nur sagen, dass dieselbe fast ausschliesslich nach den Verticalkreisen vor sich ging, so dass alle Sternschnuppen in grösserer, oder geringerer Höhe über dem Horizonte aufblitzten, und hierauf beinahe vertical sich dem Horizonte näherten; schief gegen den Horizont laufende, oder untereinander sich kreuzende Richtungen bildeten nur wenige Ausnahmen von jener allgemeinen Richtung. Wenn ich mir die Richtungen des Laufes der Mehrzahl von Sternschnuppen aufwärts verlängert dachte, schien es mir, dass dieselben in der Gegend des Perseus zusammenliefen.
Gegen 10 Uhr war Perseus nicht weit vom Zenith entfernt, und die Sternschnuppen schienen auch in einer kleinen oder grösseren Distanz von demselben aufzutauchen, und hierauf bewegten sie sich dem Horizonte zu.

In Betreff des Ortes, wo sich am meisten Sternschnuppen zeigten, lässt sich wohl nicht viel sagen, denn der ganze sichtbare Himmel war beinahe gleichmässig von Sternschnuppen bestrahlt; nur manchmal bemerkte ich eine grössere Häufigkeit im Taurus und Auriga einerseits, und zwischen dem $P$ egasus und $C y g n u s$ anderseits.

In Hinsicht des Glanzes war ungefähr $\frac{1}{10}-\frac{1}{10}$ der gesammten Anzahl von Sternschnuppen den Sternen 1. Grösse gleich, weit mely so gegen $\frac{1}{2}$ dieser Anzahl erreichte den Glanz der Sterne 2. und 3. Grösse, die ibrigen Sternschnuppen waren viel schwächer, und einige sogar kaum sichtbar. Mit wenigen Ausnahmen war die Lichtfarbe der Sternschnuppen weiss, dem Lichte der Capella ähnlich, nur einige wenige sah ich von der Farbe des Aldebaran. Die Farbe der Lichtschweife, welche bei einigen Sternschnuppen ziemlich lang und 1-3 Zeitsecunden sichtbar waren, war entweder grülich, oder röthlich; rein weisse Lichtschweife habe ich nicht gesehen.

Gegen 11 Uhr schien die Hänfigkeit der Sternschnuppen etwas abzunehmen, dafür aber war ihr Glanz ausserordentlieh prachtroll, besonders im Pegasus, wo viele von ihnen die Sterne 1. Grösse an Glanz übertrafen; an zwei der glänzendsten beobachtete ich sogar ein Zerplatzen und Funkensprühen bei ihrem Versehwinden, eine Detonation war aber nicht hörbar.

Ich bedaurte sehr das Phänomen wegen Volken nicht weiter beobachten zu können.

Warschau, 1872 November 28 . Kowalczyli.

\title{
Aus einem Schreiben des Herrn Dr. Vogel an den Herausgeber.
}

Am 27. November 1872 wurde hier ein auffallend starker Meteoritenfall beobachtet. Herr Palisa aus Pola, der die Sternwarte besuchte, hatte auf dem Wege von Bordesholm nach Bothkamp, zwischen 6 und 7 Uhr, diese auffallende Erscheinung zuerst bemerkt. Leider war die Witterung sehr ungüstig, gegen $10 \mathrm{Uhr}$ jedoch, theilte sich der Wolkenschleier und war der Himmel auf etwa 45 Minuten zum grossen Theile klar. In 3 Minuten, wurden 45 Sternschnuppen gezählt, eine Zahl die wohl kaum der Wirklichkeit entspricht, da uns jedenfalls viele Sternschnuppen durch Wolken entgingen. Die meisten dieser Sternschnuppen waren schwach, 4ter und jter Grösse und meist ron kurzer Dauer; nur 4 oder 3 hellere (lster bis zter Grösse) mit nachbleibendem Schweif, konnten in der kurzen Zeit bemerkt werden. Der Radiationspunlit war im Perseus, in der Nähe von $\beta$ Persei gelegen. Leider blieb das Wetter auch in den späteren Nachtstunden ungünstig, doch konnten uberall, wo durch eine lichte Stelle in dem dichten Wolkenschleier der Himmel auf kure Zeit sichtbar wurde, zahlreiche Sternschnuppen beobachtet werden.

$$
\text { Bothkamp, } 1872 \text { November } 29 . \quad \text { H. Vogel. }
$$

